\title{
Short Communication: Systems-based conservation and conflicts between species protection programs
}

\author{
F. Jordán ${ }^{1}$ and A. Báldi ${ }^{2}$ \\ ${ }^{1}$ The Microsoft Research-University of Trento Centre for Computational and Systems Biology, \\ Piazza Manifattura 1, Rovereto, TN, 38068, Italy \\ ${ }^{2}$ Institute of Ecology and Botany, MTA Centre for Ecological Research, \\ Alkotmány út 2-4., Vácrátót 2163, Hungary \\ Correspondence to: F. Jordán (jordan.ferenc@gmail.com)
}

Received: 9 March 2013 - Revised: 24 July 2013 - Accepted: 2 October 2013 - Published: 21 October 2013

\begin{abstract}
Although the conflict between conservation efforts and economic growth is a major topic of conservation science, the conflicts between different conservation projects are much less documented and represented in the literature. We provide an overview of some case studies where these conflicts arise and discuss how to manage and solve them. We argue that conflicts are unavoidable, and that we can find optimal and efficient solutions only by studying the holistic, macroscopic properties of whole socio-ecological systems. Novel computational solutions offer simple and efficient simulation toolkits providing indicators that can support strategic and integrative decisions from a systems perspective.
\end{abstract}

\section{Introduction}

Global biodiversity is threatened by several processes, including overexploitation, habitat loss and fragmentation. Conservation strategies traditionally focus on individual species or protected areas, but the two seemingly different approaches largely overlap. For example, the Chitawan National Park in Nepal was created to preserve the Indian rhinoceros (Rhinoceros unicornis), or the Gombe Stream National Park in Tanzania is famous for its chimpanzees (Pan troglodytes) studied by Jane Goodall. In Europe, the largest reserve system on Earth, the Natura2000 network of the European Union, was designed to protect rare species and habitats (European Commission, 1996). In the USA, the Endangered Species Act is a major force for nature conservation, and is clearly focused on rare species (National Research Council, 1995).

It is a major question whether to protect certain species directly or to protect their habitat. The Red Data Book is a collection of several indicators and vulnerability ranks that provide the basis for selecting the species worth protecting. The basic principle is rarity: the rarer, the more urgent the need to protect. Another principle, often less explicit, is com- municability: charismatic species have a higher chance of becoming flagships, even if there would be better solutions (like invertebrate keystone species, see Wilson, 1987; Simberloff, 1998; McClenachan et al., 2012). From an ecosystem viewpoint, the key question is whether the protection of a given species is optimal for managing the whole ecosystem (that may be the case for keystone species). There are increasing discussions on the perspectives of systems-based conservation: approaches based on ecosystem conservation (Rohlf, 1991; Simberloff, 1998) focusing on ecosystem functions (Schwartz et al., 2000) and ecosystem services (Chan et al., 2006) are not new, but are still insufficient at providing solutions to most practical questions.

In ecological systems, coexisting and coevolving species develop various interactions and are intimately related to each other across myriads of links. Parallel direct interactions result in the huge number of indirect effects among species. Some of these are positive, some are negative, and the mixed sign of the net effects is a major challenge to understanding and predicting (Palomares et al., 1995; Bondavalli and Ulanowicz, 1999; Yodzis, 2000). Moreover, indirect effects can be surprisingly strong (Palomares et al., 1995) and surprisingly far-reaching (Estes et al., 1998). Figure 1 

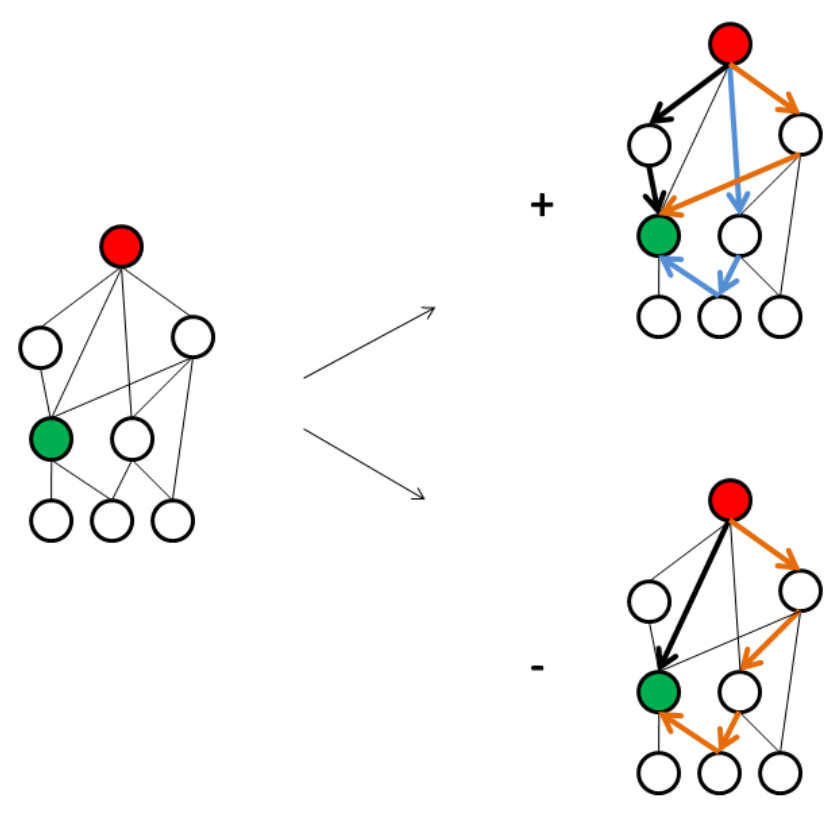

Figure 1. This small interaction network among species illustrates mixed-sign effects as a typical source of conservation conflict. Whatever we do with the red species, it will have a positive and negative influence on the green one, both across a variety of indirect pathways. Among the positive effects, we see two trophic cascades (black and orange) and a keystone predation (blue). Negative effects include predation (black) and an unnamed long indirect effect (orange).

illustrates the contrasting effects between two species in a simple toy network. Conservation efforts for one species will surely affect several others in a highly unpredictable way and in both strength (weak or strong) and sign (positive or negative). These indirect cascading effects may also influence other protected species. Some resulting conflicts are logically unavoidable: it is hard to imagine any conservation management strategy that is good for every species.

Apart from mixed-sign community effects such as predation and trophic cascade (Palomares et al., 1995), we have to face the mixed effects of landscape management solutions as well. Basically, ecological corridors are always barriers at the same time for other kinds of species. Corridor maintenance, improvement or design can be a highly efficient and useful tool in landscape and seascape (Olds et al., 2012) conservation, but adverse effects are unavoidable. The different spatial scales that two protected species use make it hard to find an integrated management plan for both (Batáry et al., 2007). For example, different spatiotemporal scales complicate conservation efforts: different species face different extinction debt (Paltto et al., 2006). It has also been demonstrated that decadal habitat use changes affect biodiversity more than contemporary management (Tilman et al., 1994; Gustavsson et al., 2007), so conservation efforts face the problem of the past-present conflict. Just like multi-species commu- nity conservation, landscape management faces the problem of handling coexisting species with contrasting habitat use behavior.

\section{Case studies}

The following examples illustrate conflicts caused by both community-level and landscape-level processes. Pyrenean chamois (Rupicapra pyrenaica) is an IUCN-listed species (least concern), with massive conservation efforts to increase its populations (e.g., hunting reserves). The chamois, however, forage on the Pyrenean larkspur (Delphinium montanum), a rare endemic perennial herb. Therefore, human conservation efforts for the two species are in fundamental conflict (Simon et al., 2001). In general, solutions seem to be harder to find if the conflict is between an animal and a plant species. This is because of different methodologies, different spatiotemporal scales and typically poor communication between specialists. In this case, it is also known that consumption by chamois is the dominant threat for the herb (even if Pyrenean larkspur may be lethal for herbivores: this is why cows do not consume it).

The protection of tree-nesting wader species in the Spanish Donana Biological Reserve has been successful, and the population of birds increased. This in turn resulted in a larger number of nests on the limited number of trees, showing higher stress and poorer condition of trees with nests than those without nests. A conservation conflict and a challenging trade-off is how to conserve both the wader populations and the valuable relict trees in the landscape (García et al., 2011).

Sometimes the distinction between the "protected area approach", the "habitat approach" and the "ecosystem approach" is not easy. These aim to focus on a geographical unit, a single species' living area or the totality of an ecological system, respectively. In the case of a protected prey (the shrike) and its protected predator (the fox), the only way to manage the conflict is to take a higher-level, more holistic systems view, whichever the larger unit of study and conservation effort is, a landscape, a habitat fragment or a subset of interacting species (Roemer and Wayne, 2003).

However, in certain cases, habitat protection favors a focal species that is competitively dominant over others. This may lead to competitive exclusion or the displacement of the competitively inferior species. Here, spatial processes (dispersal to alternative habitat patches) may be the solution, but these must often happen out of the protected area (see Oro et al., 2009). For this, habitat mosaics or networks should be managed and their functional connectivity must be maintained. Habitats to protect are not just defined based on some focal species, but their protection also has variable benefits for different species. In the example of Oro et al. (2009), a flagship gull species outcompetes the others. 
Ruscoe et al. (2011) have demonstrated experimentally that invasion and removal can have unexpected effects dominated by competitive interactions (as opposed to predation). For example, competitive release is a major source of surprise. Meso-predator release is a top-down form of this kind of unexpected consequence: here, a trophic cascade is broken and causes secondary extinction waves. Famous examples include the food chain between coyotes, a group of mesopredators such as foxes, and shrub-living birds, where the local extinction of coyote caused bird extinction by reduced control of the meso-predators (Crooks and Soulé, 1999), or the trophic cascade of killer whale, sea otter and sea urchin, where the increase of the orca population dramatically raised the number of urchins by reducing otters (Estes et al., 1998). This last example is rather like an inverse of meso-predator release, indicating that the same mechanisms can happen with a different sign.

We have briefly illustrated some examples of how common and unavoidable conservation conflicts can be. The above examples are not easy to solve: if we look for quasioptimal multi-species solutions, we need the help of modeling tools and modern computational support.

\section{The systems perspective: new tools and new concepts}

Multi-species problems cannot be solved by local studies and single-species experts. In order to preserve diversity, different diversity of databases and analytical tools are needed (Michener and Jones, 2012). Recent monitoring efforts have made it possible to store huge amounts of data on the genetics, abundance, distribution, movement, interactions and phenology of a large number of species. Novel computational tools are ready to support the use of ecosystem-level indicators (EwE, Christensen and Walters, 2004) to evaluate landscape connectivity (Conefor Sensinode, Saura and Torné, 2009) or to perform food web simulations (BlenX, Livi et al., 2011; Jordán et al., 2012).

These methods do not solve problems, but can provide quantitative information to support decision-making. Results may suggest potentially strong indirect effects and avoid surprising outcomes. Also, sensitivity analysis may suggest key species and interactions, providing quantitative priorities for conservation. For example, a simulation model of the Prince William Sound ecosystem suggests that ecosystem dynamics is mostly sensitive to disturbing the group of "nearshore demersals" (Livi et al., 2011). Figure 2 shows the relative importance of different trophic groups in this simulated food web: disturbing the organisms represented by larger nodes generates a larger simulated community response in the ecosystem. Before translating theoretical predictions obtained from computational modeling into practical guidelines for conservation, it is important to verify empirically the predictions using experiments. Furthermore, the model can be used to sug-

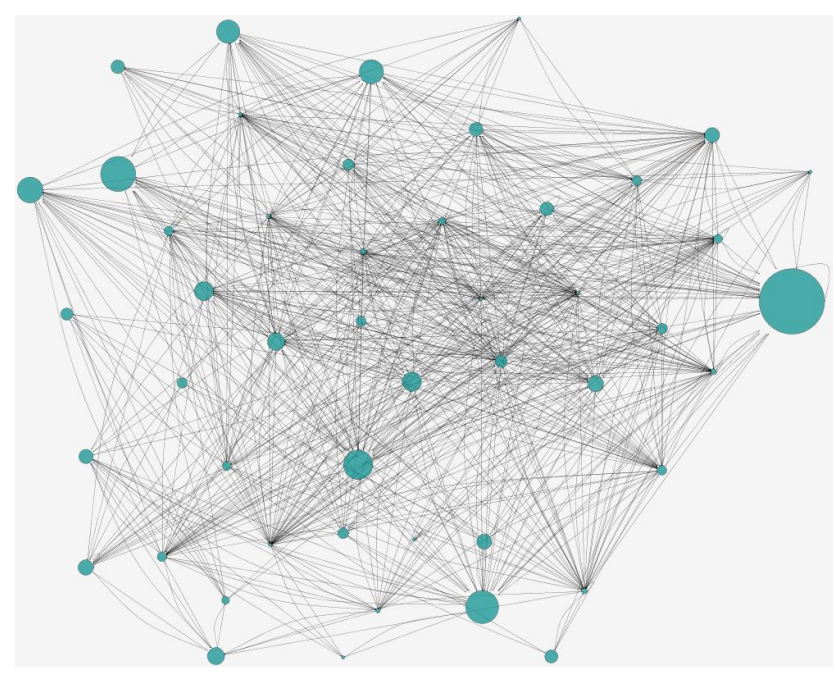

Figure 2. The food web of the Prince William Sound model (after Okey, 2004; Okey and Wright, 2004). Producers and top predators are at the bottom and at the top, respectively, according to convention. Trophic groups are arranged by trophic level. The size of the nodes is proportional to the community response their disturbance generated in the simulations (Livi et al., 2011).

gest concrete experiments, allowing us to collect new data in a potentially more efficient and useful way. Several smallerscale studies have already identified hidden, indirect interactions and suggested focal species for further research, in order to better understand particular conservation issues (see Palomares et al., 1995; Crooks and Soulé, 1999).

A major advantage of these models is that they are relatively fast, simple and cheap. Moreover, their complexity can be calibrated and adapted to a particular situation. The amount of real data required to parameterize these models can be a disadvantage, but this amount can be calibrated, and the reality/data-richness of the model can be fine-tuned to particular situations. We also note that large amounts of unused and not-yet-evaluated data exist and are a ripe target for integrative systems modeling. Simple toy models as well as sophisticated complex models can equally be of use, as a function of the problem (cf. Yodzis, 2000). Before making massive efforts and investing lots of resources in protection programs, it is worth double-checking their multi-species consequences. Modeling approaches allow us to quantify whether two planned programs are in conflict or if they display hidden synergies, giving a strong tool to planners that are deciding between different conflicts.

\section{Conclusions}

Even if single-species management is easier to understand and communicate, in many cases it is clearly expensive, inefficient and, even more importantly, conceptually wrong. Since there is a diversity of interspecific interactions among 
species, it is not really surprising that whatever effort we take to preserve one species will have advantages and disadvantages for many other species in the same ecosystem. We cannot be satisfied if all birds and mammals are winners if there is a large number of (predominantly and typically) invertebrate losers. A holistic, systems-based ecosystem approach is more conceptually sound and efficient, and may provide multi-species solutions in conservation efforts.

Aided by increasingly large databases and sophisticated computational tools, we are entering an era when ecosystemlevel modeling can be really feasible, predictive and applicable. Systems-based management is slowly becoming reality. For example, handling stochasticity (Rohlf, 1991) and focusing on the diversity of processes (Simberloff, 1998) are old problems that we are on the cusp of addressing.

Facing the reality of unpredictability in ecological systems, the pragmatic solution for managing conflicts and setting priorities should involve some kind of adaptive management (Simberloff, 1998). Computational tools provide support by using fast and simple toy models and strategic decision-making (Yodzis, 2001). The next problem on the horizon is the societal context: according to Peterson et al. (2004), the political regime may also have an effect on the success in solving conflicting conservation efforts. Of course, the final challenge is managing multi-species socioecological conflicts (Holling, 2001), but first we must be able to manage conservation conflicts between projects focusing on only two species.

Acknowledgements. F. Jordán is grateful to Thomas A. Okey for providing data. Federico Vaggi is kindly acknowledged for great comments.

Edited by: K. Jax

Reviewed by: D. Alagador and U. Sinsch

\section{References}

Batáry, P., Báldi, A., and Erdős, S.: Grassland versus non-grassland bird abundance and diversity in managed grasslands: local, landscape and regional scale effects, Biodivers. Conserv., 16, 871881, 2007.

Bondavalli, C. and Ulanowicz, R. E.: Unexpected effects of predators upon their prey: the case of the American alligator, Ecosystems, 2, 49-63, 1999.

Chan, K. M. A., Shaw, M. R., Cameron, D. R., Underwood, E. C., and Daily, G. C.: Conservation planning for ecosystem services, PLoS Biol., 4, e379, doi:10.1371/journal.pbio.0040379, 2006.

Christensen, V. and Walters, C. J.: Ecopath with Ecosim: methods, capabilities and limitations, Ecol. Model., 172, 109-139, 2004.

Crooks, K. R. and Soulé, M. E.: Mesopredator release andavifaunal extinctionsin a fragmented system, Nature, 400, 563-566, 1999.

Estes, J. A., Tinker, M. T., Williams, T. M., and Doak, D. F.: Killer whale predation on sea otters linking oceanic and nearshore ecosystems, Science, 282, 473-476, 1998.
European Commission: Interpretation Manual of European Union Habitats, version EUR 15, Natura 2000, compiled by: Romao, C., DG XI - D2, Brussels, 1996

García, L. V., Ramo, C., Aponte, C., Moreno, A., Domínguez, M. T., Gómez-Aparicio, L., Redondo, R., and Marañón, T.: Protected wading bird species threaten relict centenarian cork oaks in a Mediterranean Biosphere Reserve: A conservation management conflict, Biol. Conserv., 144, 764-771, 2011.

Gustavsson, E., Lennartsson, T., and Emanuelsson, M.: Land use more than 200 years ago explains current grassland plant diversity in a Swedish agricultural landscape, Biol. Conserv., 138, 4759, 2007.

Holling, C. S.: Understanding the complexity of economic, ecological, and social systems, Ecosystems, 4, 390-405, 2001.

Jordán, F., Gjata, N., Mei, S., and Yule, C. M.: Simulating food web dynamics along a gradient: quantifying human influence, PLoS ONE, 7, e40280, doi:10.1371/journal.pone.0040280, 2012.

Livi, C. M., Jordán, F., Lecca, P., and Okeyet, T. A.: Identifying key species in ecosystems with stochastic sensitivity analysis, Ecol. Model., 222, 2542-2551, 2011.

McClenachan, L., Cooper, A. B., Carpenter, K. E., and Dulvy, N. $\mathrm{K}$. : Extinction risk and bottlenecks in the conservation of charismatic marine species, Conservation Letters, 5, 73-80, 2012.

Michener, W. K. and Jones, M. B.: Ecoinformatics: supporting ecology as a data-intensive science, Trends Ecol. Evol., 27, 85-93, 2012.

National Research Council (NRC): Science and the Endangered Species Act, National Academy Press, Washington DC, 1995.

Okey, T. A.: Shifted community states in four marine ecosystems: some potential mechanisms, Ph.D. thesis, University of British Columbia, Vancouver, 2004.

Okey, T. A. and Wright, B. A.: Toward ecosystem-based extraction policies for Prince William Sound Alaska: integrating conflicting objectives and rebuilding pinnipeds, B. Mar. Sci., 74, 727-747, 2004.

Olds, A. D., Connolly, R. M., Pitt, K. A., and Maxwell, P. S.: Habitat connectivity improves reserve performance, Conservation Letters, 5, 56-63, 2012.

Oro, D., Pérez-Rodríguez, A., Martínez-Vilalta, A., Bertolero, A., Vidald, F., and Genovart, M.: Interference competition in a threatened seabird community: A paradox for a successful conservation, Biol. Conserv., 142, 1830-1835, 2009.

Palomares, F., Gaona, P., Ferreras, P., and Delibes, M.: Positive effects on game species of top predators by controlling smaller predator populations: an example with lynx, mongooses, and rabbits, Conserv. Biol., 9, 295-305, 1995.

Paltto, H., Nordén, B., Götmark, F., and Franc, N.: At which spatial and temporal scales does landscape context affect local density of Red Data Book and Indicator species?, Biol. Conserv., 133, 442-454, 2006.

Peterson, M. N., Allison, S. A., Peterson, M. J., Peterson, T. R., and Lopez, R. R.: A tale of two species: habitat conservation plans as bounded conflict, J. Wildlife Manage., 68, 743-761, 2004.

Roemer, G. W. and Wayne, R. K.: Conservation in conflict: the tale of two endangered species, Conserv. Biol., 17, 1251-1260, 2003.

Rohlf, D. J.: Six biological reasons why the Endangered Species Act doesn't work - and what to do about it, Conserv. Biol., 5, 273-282, 1991. 
Ruscoe, W. A., Ramsey, D. S. L., Pech, R. P., Sweetapple, P. J., Yockney, I., Barron, M. C., Perry, M., Nugent, G., Carran, R., Warne, R., Brausch, C., and Duncan, R. P.: Unexpected consequences of control: competitive vs. predator release in a fourspecies assemblage of invasive mammals, Ecol. Lett., 14, 10351042, 2011.

Saura, S. and Torné, J.: Conefor Sensinode 2.2: A software package for quantifying the importance of habitat patches for landscape connectivity, Environ. Modell. Softw., 24, 135-139, 2009.

Schwartz, M. W., Brigham, C. A., Hoeksema, J. D., Lyons, K. G., Mills, M. H., and van Mantgem, P. J.: Linking biodiversity to ecosystem function: implications for conservation ecology, Oecologia, 122, 297-305, 2000.

Simberloff, D.: Flagships, umbrellas, and keystones: is singlespecies management passé in the landscape area?, Biol. Conserv., 83, 247-257, 1998.
Simon, J., Bosch, M., Molero, J., and Blanché, C.: Conservation biology of the Pyrenean larkspur (Delphinium montanum): a case of conflict of plant versus animal conservation?, Biol. Conserv., 98, 305-314, 2001.

Tilman, D., May, R. M., Lehman, C. L., and Nowak, M. A.: Habitat destruction and the extinction debt, Nature, 371, 65-66, 1994.

Wilson, E. O.: The little things that run the world, Conserv. Biol., 1, 344-346, 1987.

Yodzis, P.: Diffuse effects in food webs, Ecology, 81, 261-266, 2000.

Yodzis, P.: Must top predators be culled for the sake of fisheries?, Trends Ecol. Evol., 16, 78-84, 2001. 